Viso - Cadernos de estética aplicada Revista eletrônica de estética

ISSN 1981-4062

№ 8, jan-jun/2010

http://www.revistaviso.com.br/

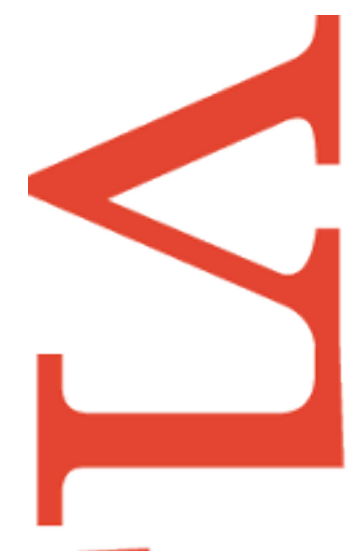

\title{
Adorno e Mário de Andrade: duas visões da criação pela música \\ Henry Burnett
}

Universidade Federal de São Paulo (UNIFESP)

Guarulhos, Brasil 


\section{RESUMO}

Adorno e Mário de Andrade: duas visões da criação pela música

O artigo propõe uma primeira aproximação entre alguns dos estudos estético-musicais de Theodor Adorno e Mário de Andrade, a partir do material musical popular explorado por cada um deles. Contemporâneos, ambos escreveram sobre as diversas esferas musicais a partir dos efeitos gerados pela técnica resultante da hegemonia do capitalismo, tanto nos Estados Unidos como no Brasil. O ambiente histórico em que cada um viveu, e suas distintas formas de abordagem, imprimiram semelhanças e diferenças nas suas conclusões. Essas particularidades podem ajudar a compreender a história da música estadunidense e brasileira no século XX.

Palavras-chave: Theodor Adorno - Mário de Andrade - música popular - música brasileira - jazz - indústria cultural

\section{ABSTRACT}

Adorno and Andrade: two visions of creation by music

The article proposes a first approximation between some aesthetic-musical studies of Theodor Adorno and Mario de Andrade, from the popular musical material explored by each of them. Contemporaries, both wrote about the several musical spheres from the effects generated by the technique resulting from the hegemony of capitalism, both in the United States and Brazil. The historical environment in which each lived, and their distinct approaches, printed similarities and differences in their conclusions. Those characteristics may help to understand the history of American and Brazilian music in the twentieth century.

Keywords: Theodor Adorno - Andrade - popular music - Brazilian music - jazz cultural industry 


\section{BURNETT, H. "Adorno e Mário de Andrade: duas visões da criação pela música". In: Viso: Cadernos de estética aplicada, v. IV, n. 8 (jan-jun/2010), pp. 85-97.}

DOI: $10.22409 / 1981-4062 / v 8 i / 90$

Aprovado: 21.06.2010. Publicado: 10.07.2010.

(C) 2010 Henry Burnett. Esse documento é distribuído nos termos da licença Creative Commons Atribuição-NãoComercial 4.0 Internacional (CC-BY-NC), que permite, exceto para fins comerciais, copiar e redistribuir o material em qualquer formato ou meio, bem como remixá-lo, transformá-lo ou criar a partir dele, desde que seja dado o devido crédito e indicada a licença sob a qual ele foi originalmente publicado.

Licença: http://creativecommons.org/licenses/by-nc/4.0/deed.pt_BR

Accepted: 21.06.2010. Published: 10.07.2010.

(C) 2010 Henry Burnett. This document is distributed under the terms of a Creative Commons Attribution-NonCommercial 4.0 International license (CC-BY-NC) which allows, except for commercial purposes, to copy and redistribute the material in any medium or format and to remix, transform, and build upon the material, provided the original work is properly cited and states its license. License: http://creativecommons.org/licenses/by-nc/4.0/ 
O titulo deste texto joga com um dado pouco ou talvez nunca mencionado quando se estuda a música popular brasileira sob o foco da filosofia da música de Theodor Adorno: sua proximidade cronológico-temática em relação ao musicólogo paulista Mário de Andrade. Salvo engano, ainda não se tratou de alguns cruzamentos possíveis entre os dois autores. Talvez a aparente distância teórica e conceitual que os separa seja um dos motivos. Não se trata de um vínculo, isso deve ficar claro, antes de uma coincidência, ou uma confluência de dados que, ao fim, podem ampliar de algum modo tal perspectiva restrita.

Vejamos: a) ambos refletiram sobre a música a partir de uma mesma preocupação, mais exposta em Adorno e mais nuançada em Mário: a hegemonia do capitalismo e seus efeitos sobre a música; b) suas análises têm em comum a característica de partir do mesmo lugar: a dinâmica da música veiculada através dos discos e das rádios comerciais. A despeito dessa proximidade inequívoca, eles permanecem isolados e desconectados nos estudos culturais. Embora existam muitos pontos de contato, gostaria de abordar um em especial: as mudanças sofridas na música popular no interior dos processos de produção comercial.

Para que se possa refletir sobre os caminhos deste estilo no Brasil, alguns estudos de Adorno são fundamentais, ainda que a canção popular não fosse seu foco - a não ser de um ponto de vista extremamente crítico. É comum considerar suas conclusões limitadas para dar conta do sentido amplo que a canção popular atingiu no âmbito da cultura nacional; mas pode ser um caminho arriscado. Adorno não deixou um método de aplicação e muito menos aberta uma possibilidade de revigoramento do estilo, que até hoje está colado a produções cinematográficas e televisivas na forma com que ele diagnosticou. Um prognóstico desde sempre inatacável. O que precisamos lembrar é que ele dedicou especial atenção à música em muitos de seus estudos, deixando clara a importância de tratá-la seriamente dentro dos círculos da filosofia e da sociologia acadêmicas. Sem isso, para ele, a sociedade onde essa música se desenvolveu não poderia ser plenamente compreendida. Isso significa, no caso de uma aproximação com o Brasil, assumir sua perspectiva crítica sem temer as consequências.

Mário de Andrade, por sua vez, desenvolveu análises marcantes a respeito da música brasileira num momento paralelo à própria formação de nossa musicalidade, ou, talvez seja mais preciso falar, de nossa estilística musical. Seus estudos, ainda hoje, são importantes para quem se debruça sobre a história e a teoria da arte musical popular e erudita, ainda que sua visão a respeito da então nascente música comercial tenha sido contaminada por algum excesso de zelo e possa ser revista em muitos pontos, especialmente no que concerne ao pendor nacionalista com que lidou com domínios do folclore, imaginando ser possível quase "domesticá-lo" para fazer dele fonte das criações eruditas. Ao aproximá-los, tentaremos mostrar que, de modos diversos, ambos estiveram preocupados com os destinos da música popular e dos efeitos educacionais de sua audição comercial. Mas também para confirmar que são incontornáveis ainda hoje. 


\section{Adorno e a música popular}

Quando Adorno escreve o prefácio ao livro Filosofia da nova música, de 1948, ele mesmo destaca o ensaio "O fetichismo na música e a regressão da audição", de 1938, como um momento determinante de seus estudos sobre a música. ${ }^{1}$ Sua intenção, no texto de 1938, era apontar as modificações que a percepção musical sofria no interior da produção comercial padronizada (estandardizada) de cultura, alterações que teriam atingido não só o gosto, mas a própria faculdade de audição dos ouvintes. O texto sobre a audição, junto com outro do mesmo período, "Sobre música popular" (escrito em colaboração com George Simpson, que trabalhou em conjunto com Adorno no The Princeton Radio Research Project, uma pesquisa sobre os fenômenos musicais das emissões radiofônicas nos Estados Unidos) ${ }^{2}$ oferecem subsídios interessantes para uma aproximação mais estreita com Mário de Andrade.

Sempre que Adorno escreveu diretamente sobre a música e a indústria cultural, fez questão de marcar uma diferença entre a música popular e a chamada música clássica, que ele chama de "séria" [Serious music]. Tal posição não significava uma parcialidade em proveito de uma música erudita que seria hierarquicamente superior à popular, antes parece ter sido gerada pela uniformização dos estilos veiculados nas rádios comerciais, que ele conhecia desde antes do exílio norte-americano, ainda na Alemanha. E mais do que isso: o conceito de popular utilizado por Adorno parece sempre vinculado de forma muito próxima ao funcionamento e à especificidade do mercado norte-americano. O que Adorno chama de popular não tem um correspondente exato no Brasil, como esclarece Rodrigo Duarte.

\footnotetext{
Registra-se aqui uma confusão, que não é normalmente feita por Adorno nos textos em alemão, entre 'música de massa' e 'música popular'. Para um norte-americano parece quase impossível fazer essa distinção, já que a autocompreensão dos EUA como uma cultura própria, independente da europeia, se dá às vésperas da consolidação dos monopólios culturais. No Brasil, ainda podemos, felizmente, diferenciar - pelo menos em termos parciais - a cultura popular mais enraizada, daquela totalmente fabricada para o consumo, ainda que tenha raízes supostamente populares. ${ }^{3}$
}

Disso podemos deduzir que o resultado dos processos culturais específicos do Brasil não podem ser postos à luz das análises de Adorno desconsiderando questões pontuais; uma entre tantas, o dado de que aqui não se produziu música séria na mesma proporção que a popular por carências musicais, mas que o cancioneiro popular é hegemônico por conta de um imperativo histórico. $\mathrm{O}$ valor final deste imperativo pode até ser julgado adequado, rico ou não, mas nosso problema não é de julgamento.

O que está, digamos, para além de Adorno, é o papel diferenciado que as canções populares ocupam no Brasil. Um papel que beira a saturação, bem verdade, mas que não pode ser, pelo menos por essa razão, descartado. Para ficar em um exemplo, bastaria mencionar sua função de emancipação enquanto agente político que foi em momentos-chave da história do Brasil; tal função já as distancia do cenário discutido por 
Adorno, onde as canções seriam mais sustentáculos da ideologia hegemônica que, propriamente, possibilidades de criticá-la. Mesmo quando Adorno reflete sobre o jazz, parece vê-lo apenas como fruto daquele processo de padronização, o que parece restritivo mesmo que pensemos apenas no contexto americano. Ele não atribui ou não pôde atribuir quase nenhuma importância ao cancioneiro popular? Veremos adiante como este diagnóstico pode ser apressado e em nada colaborar para um bom uso de suas análises para uma crítica musical contemporânea. Antes, vejamos como Mário pensava a questão.

\section{Mario de Andrade e um projeto de Brasil}

Abancado à escrivaninha em São Paulo Na minha casa da rua Lopes Chaves De sopetão senti um friúme por dentro.

Fiquei trêmulo, muito comovido

Com o livro palerma olhando pra mim.

Não vê que me lembrei lá no norte, meu Deus!

[muito longe de $\mathrm{mim}$,

Na escuridão ativa da noite que caiu,

Um homem pálido, magro de cabelo escorrendo nos olhos

Depois de fazer uma pele com a borracha do dia,

Faz pouco se deitou, está dormindo.

Esse homem é brasileiro que nem eu...

(Mário de Andrade, "Descobrimento”, de Dois Poemas Acreanos)

O poema mostra que Mário caminhou na contramão de Adorno quando estudou e tentou caracterizar a música popular. Ele já sugere no poema que o Brasil era muito maior que a cidade de São Paulo, onde vivia e trabalhava, e que o essencial para qualquer projeto de país, já naquele momento, passava pelo entendimento de nosso não-lugar, de nossa "impureza" cultural. Mário via no popular, isto é, no folclórico, algo que precisava ser conservado. A diferença entre a visão de Mário e a de Adorno é diretamente proporcional ao nível de profundidade da implantação do capitalismo no Brasil. Enquanto Adorno vê os "resíduos pré-capitalistas" se dissolverem, Mário encontra-os vivos, ainda que chegue a subestimar sua continuidade, preocupado com o advento do rádio e da indústria de discos.

Desde muito cedo, Mário não estava alheio aos fenômenos de massa e compreendia onde e como esses fenômenos agiam sobre a música popular do Brasil. Suas observações, frutos de grande erudição e das viagens que ele empreendeu e organizou 
país afora, mostram que, desde as origens, nossa música foi alimentada por uma teia de influências de grande complexidade. Com isso, se quer confirmar, com Adorno, que o modo de produção capitalista foi avassalador, mas que, contra ele, a música popular no Brasil não foi abatida como, eventualmente, se deu nos EUA, se acatamos sua análise sem restrições. Mas como é quase consensual, a despeito das diferenças entre o jazz e os ritmos brasileiros na primeira metade do século $X X$, Adorno, repito, não parece ter enxergado devidamente a importância e o significado histórico do gênero nos EUA.

Mário, por sua vez, não recebeu passivamente a chegada da indústria cultural no país, ao contrário, quando passou uma temporada mais longa no Rio de Janeiro, e presenciou os primeiros concursos de escolha dos sambas que iriam acompanhar os desfiles, afirmou que:

[...] o que aparece nestes concursos, não é samba do morro, não é coisa nativa nem muito menos instintiva. Trata-se exatamente de uma sub-música, carne para alimento de rádios e discos, elemento de namoro e interesse comercial, com que fábricas, empresas e cantores se sustentam, atucanando a sensualidade fácil de um público em via de transe. Se é certo que, vez por outra, mesmo nesta sub-música, ocasionalmente ou por conservação de maior pureza inesperada, aparecem coisas lindas ou tecnicamente notáveis, noventa por cento desta produção é chata, plagiária, falsa como as canções americanas de cinema, os tangos argentinos ou fadinhos portugas de importação. ${ }^{4}$

Mário visualizou a música popular como um documento da identidade do povo, depositária de elementos históricos e emocionais. Vem daí sua repulsa mesmo a um momento elementar da ligação entre os sambistas e o mercado. Essa ligação da música com as camadas populares talvez faça pouco sentido fora do Brasil, ou da América Latina - o que isenta de algum modo Adorno, cuja visão estrutural da música não podia coadunar com a miscigenação resultante do colonialismo e de seus reflexos na música. No ensaio "A evolução social da música no Brasil", de 1939, Mário afirma que "ela [a música brasileira] terá que se elevar ainda um dia à fase que chamarei de Cultural, livremente estética, e sempre se entendendo que não pode haver cultura que não reflita as realidades profundas da terra em que se realiza". ${ }^{5}$ Esse produto oculto de um Brasil desconhecido remete a uma afirmação clássica de Adorno, "[...] a música atual, em sua totalidade, é dominada pela característica de mercadoria: os últimos resíduos précapitalistas foram eliminados"; ${ }^{6}$ sua descrição ainda hoje destoa fortemente de nossa realidade, bastando pensar na atualidade do uso do termo cultura popular.

Ainda no texto fortemente melancólico que Mário escreveu depois da passagem pelo Rio, ele relembra um testemunho que o aproxima licenciosamente de outro frankfurtiano, Walter Benjamin; trata-se de um fragmento importante. $O$ belo trecho diz o seguinte:

Nunca me esqueci daquela esplêndida resposta dada a Paul Laforgue por um cantador popular: 'Como não sei ler nem escrever, para guardar a história tive que fazer uma cantiga com ela'. O valor mnemônico da canção é questão pacífica que ninguém mais lembra de discutir. Ora, toda uma população religiosamente atenta, a decorar textos raramente estúpidos, mas em que se faz da tara flor de ostentação, não deixa de 
preocupar seu bocado. É sempre trágico imaginar que, à maneira do cantador de Paul Laforgue, se estejam fazendo tais canções [a dos concursos] para não esquecer tais histórias... ${ }^{7}$

A memória musical do cantador popular como um documento da história perdida deveria motivar elogios de Mário de Andrade, no entanto, sua impressão parece negativa - ele acha trágico esse modo de resguardar o passado, amparado pela memória musical. Em sua observação, salta aos olhos uma distinção sutil, mas determinante: o cantador popular já não é o sambista que inscreve sua música num concurso, mas a figura do criador que está ligado ao mundo rural, folclórico - Mário não abandonaria esse ideal. Que imagem melhor nós poderíamos sugerir da função social do canto popular? No entanto, Mário ignora esse poder, talvez porque não pudesse saber àquela altura que, nas décadas seguintes, a mesma força mnemônica que ele encontra ativa nos primeiros concursos seria apartada da organização carnavalesca hiperfetichizada, e seria determinante para a permanência de elementos tradicionais em meio à derrocada da arte musical descompromissada.

\section{Frente a frente}

Trata-se aqui, como se pode perceber, menos de uma confrontação entre Mário de Andrade e Adorno, mas antes de um cotejamento com a finalidade de destacar não apenas suas distintas percepções da música popular e seus efeitos criativos e educativos, mas principalmente suas conclusões acerca dos efeitos sociais da música popular no Brasil e nos EUA.

Mário de Andrade tinha como preocupação central a definição de uma música brasileira, que ele gostaria de chamar de definitiva, uma vontade quase sempre movida em nome de um nacionalismo que foi se modificando com o passar do tempo, tornando-se mais brando. Adorno, preocupado de certa forma com as mesmas questões, escrevia a partir de uma negação da ideia de afirmações nacionalistas - se consideramos a condição de exilado nos EUA e as razões que o levaram para lá, o nazismo e suas consequências. De pronto, precisamos atentar para a diferença entre esses dois nacionalismos. Podemos um tanto grosseiramente dizer que, em Mário, ele é cultural e em Adorno, político. Não é, entretanto, uma distinção simples.

Quando Mário iniciou seus estudos, a música brasileira nem sequer estava definida estilisticamente. Esse estabelecimento era importante, pois ele achava que disso dependia nossa afirmação como nação. A partir deste programa desenvolveu grande parte de seus estudos, mormente aqueles escritos depois de 1924. Hoje, ao relermos seus textos, nos parece, em certo sentido, desbaratada sua intenção de inventar uma música capaz de representar o éthos do país. Mas é preciso reler Mário tentando desvendar uma de suas intenções mais determinantes, a defesa daquilo que julgava ser o verdadeiro Brasil, isto é, aquilo que, por trás da capa nacionalista, existia de marcante 
na idéia de uma verdade brasileira que ele só reconhecia na cultura popular. Estamos aqui no terreno movediço da identidade nacional. Considerando que o material musical recolhido por Mário em suas viagens - à Amazônia em 1927, ao Nordeste em 1928-9 e, principalmente, com a Missão de Pesquisas Folclóricas organizada por ele em 1938 ainda hoje pode ser identificado em várias regiões do Brasil, mais de 60 anos depois, no mínimo aquela intuição tem algo a nos dizer.

Pode ser arriscado tentar sustentar, a partir de Mário de Andrade, a ideia de uma resistência afirmativa desse traço cultural semi-arcaico. A primeira impressão quando se ouve essa produção nos dias de hoje é a de que nada mudou. Essa permanência da cultura popular pode ser lida de muitas formas. A primeira, e a que mais nos interessa aqui, é o que isso pode significar de um ponto de vista social. Se nos EUA, acompanhando Adorno, já na década de 30 aqueles resíduos pré-capitalistas haviam sido eliminados, o que explica sua permanência no Brasil?

Podemos definir com certa clareza as intenções de Mário de Andrade em seus estudos musicais, mas a ideia de uma música nacionalista pode muitas vezes ser compreendida como uma tentativa despropositada de afirmação do Brasil importado contra o Brasil autêntico, de uma defesa de certo passadismo, de um Brasil intocável etc. No caso de Mário, modernista por princípio, essa interpretação é equivocada.

Esse nacionalismo também deve ou pode ser visto levando-se em conta o lugar destacado do conceito de raça, povo e cultura - quase sempre sinônimos para Mário dentro de uma perspectiva que estava interligada com questões amplas da história da música. Isso significa que seus estudos não são uma tentativa de isolar o Brasil do resto do mundo, mas uma busca pela afirmação nacional a partir de questões de ordem estética e linguística.

Convicto de dar caráter social à criação musical, Mário de Andrade voltou-se para o nacionalismo, mesmo porque a música brasileira, até então, com poucas exceções, achava-se totalmente subjugada à tradição europeia. Os últimos modelos românticos, aqui dominantes, tornavam-se tradicionalistas na Europa e nacionalizar a música brasileira era não só caracterizá-la, mas também modernizá-la, dando, assim, uma contribuição significativa para o impasse da música ocidental pós-romântica. Passaríamos da imitação para a criação. ${ }^{8}$

Podemos deduzir algo óbvio do comentário acima: quando Mário apresenta seu projeto aos compositores nacionais, no Ensaio sobre a música brasileira, simplesmente não havia uma música urbana estabelecida. Se havia, ainda não Ihe parecia digna de nota. Por isso, todo o projeto de Mário joga com duas esferas, a cultura popular folclórica e a música erudita, chamada de "artística"; a música popular comercial dava passos decisivos pelas ondas do rádio, mas Mário não parecia acreditar em sua permanência enquanto uma esfera representativa da cultura nacional. Era para ele, no rigor do termo, música ligeira, passageira. 
A proposta era clara e deveria ser desenvolvida como um programa. O material folclórico eram os brasileiros. Se não estávamos desenvolvidos a ponto de estabelecermos uma representação propriamente "artística", isso sim era digno de correção,

[...] se na música folclórica, fruto da mistura espontânea de contribuições inter-raciais indígena, africana e europeia - já havia elementos identificáveis com o ambiente brasileiro, nela deveriam os compositores cultos procurar material de trabalho. A estética nacionalista baseava-se em premissas interligadas: se a música expressa a alma de um povo, os modelos escolares europeus caracterizavam-se como imposições colonizadoras. Para Mário, alguma particularidade vinha se desenvolvendo assistematicamente na música feita no Brasil, desde os tempos coloniais, marcando-a com um certo "ruim esquisito" (expressão herdada de Manuel Bandeira) distinguindo, nas obras dos compositores nacionais, esse elemento identificador nativo. ${ }^{9}$

Um bom modo de compreender o lugar da música popular urbana para Mário de Andrade é conferir alguns dos seus comentários sobre os discos de sua coleção pessoal. Utilizaremos aqui o volume A música popular na vitrola de Mário de Andrade; as 161 faixas foram selecionadas apenas entre aquelas consideradas 'música popular urbana e folclórica', segundo esclarece a organizadora tomando a designação do próprio Mário.

O tempo inteiro seus comentários apontam para uma separação entre aquilo que já pertence ao domínio "artístico", ainda que veiculado no rádio, e o que representa a cultura popular "corretamente", ou se dela já se afastou como uma degenerescência do original. É nessa classificação que podemos encontrar a tensão relacionada aos primeiros registros comerciais. Se os temas remetem ao reconhecível, bem, caso contrário, Mário os condenava. Como sobre a gravação de Moreira da Silva para "Vejo lágrimas": "Vejo lágrimas é notável como dicção ruim e bom caráter vocal brasileiro. A nasalação é magnífica e a rítmica do fraseado estupenda" (Carnaval de 1933. Comentário anotado na capa do disco).

Em outra passagem sobre a mesma faixa, lemos:

Ainda nesse sentido, poderíamos citar o samba Vejo lágrimas, também do Carnaval de 1933. O solista, sr. Antônio Moreira da Silva, apresenta uma voz de timbração deliciosa, profundamente nossa, carioca, um nasal quente, sensual, bem 'de morro'. A dicção está cheia de defeitos ortográficos e na própria entoação, embora uma vez só, fere-nos um 'tãins' (tens) aportuguesado, insuportável no meio de tanta brasileirice de música e de timbre. ${ }^{10}$

Importante de se notar que nessa "condenação" não está em jogo apenas aquilo que é bom ou ruim, mas principalmente aquilo que não é "brasileiro", dentro dessa visão de algo que não é originalmente nosso, antes um pastiche do que ouvimos dos Europeus ou Norte-Americanos. Mário não queria apenas utilizar o material folclórico como um sedimento sonoro sobre o qual seria criada nossa grande música, ele também queria demonstrar que o Brasil não era um "não-sei-quê", impreciso, vulgar; nós já existíamos, mas essa existência precisava ser lapidada até atingir o estatuto de representação estética. Como um esclarecimento, Mário afirma sobre sua coleção de discos. 
Sempre é preciso saber que muitos discos desta minha coleção, quase todos os Victor [gravadora da época] até pouco mais de 250 me foram dados prá coleção. D’aí a posse de coisas como estas que aliás são ótimas pra quando precisar citar porcarias absolutas (Comentário às canções de Marques da Gama, na faixa Vai sair bagagem, e de C. Cardoso, faixa Mulambo, sambas interpretados por Sílvio Caldas e Orquestra Victor).

Mais adiante:

O maxixe de Nazareth é uma perfeição. Admiravelmente bem compreendido como caráter instrumental de criação melódica. E bem típico do maxixe 'tango' de Nazareth. A outra face [do disco] é roubada de uma toada rural qualquer que não me lembro nem título nem versos agora (Comentário anotado na capa do disco de Ernesto Nazareth, sobre a faixa Quebra-cabeças, com Orquestra Pan American do Cassino Copacabana e Jota Machado e Cangote raspado, com Francisco Alves).

É precisamente esse "não-sei-quê" - para usar uma forma própria utilizada por Mário no Ensaio - que nos interessa desvendar com vagar. Visto à distância de várias décadas, não é difícil ver no nacionalismo de Mário um equívoco e nesse "não-sei-quê" um viés de certa xenofobia. Nada mais precipitado. Basta pensarmos em uma polêmica muito próxima de nós para percebermos que a questão que estava no pano de fundo do projeto de Mário era maior que o próprio programa nacionalista na forma com que ele imaginava. Estamos falando da sempre revivida discussão sobre o que é nacional, reacendida algum tempo atrás pela crítica de Ariano Suassuna contra o movimento Manguebit.

Nem precisamos ir longe: Ariano ocupava na polêmica, podemos dizer assim, o lugar de Mário. Para evitar simplificações, digamos que a verdade do Maracatu recifense parecia abalada pela abertura ao pop elaborada por Chico Science e a Nação Zumbi. Agora retomemos Mário e sua intuição de que repousava na cultura popular a mesma verdade que Suassuna parece querer resguardar. Até que ponto Mário e Ariano estariam equivocados sobre essa ideia de uma verdade cultural do Brasil?

No Ensaio sobre a música brasileira, Mário afirma que o desejo pelo exótico brasileiro, que ele dizia notar entre os europeus, Ihe chegava como um conselho, que the sugeria a aproximação com os ameríndios; então ele foi categórico: não era no índio, pelo menos não só nele, que se encontrava o Brasil de verdade. ${ }^{11}$ Suas impressões permitem entender seu nacionalismo de modo bem menos caricato; era no povo do Brasil que residia essa verdade, pois Mário considerava o Brasil pleno de identidade, e já estabelecido culturalmente àquela altura. Isso significa que o amálgama sintetizado na forma folclórica guardava essa veracidade e essa representação da nação. Tudo que Adorno via desaparecer nos EUA, Mário via rejuvenescer aqui, ainda que temeroso de seu fim.

Sabemos agora que o problema para ele era, curiosamente, a forma de apresentação do material, que considerava de algum modo insuficiente para a percepção estética clássica. Isso explica o comentário crítico de José Miguel Wisnik: 
O popular pode ser admitido na esfera da arte quando, olhado à distância pela lente da estetização, passa a caber dentro do estojo museológico das suítes nacionalistas, mas não quando, rebelde à classificação imediata pelo seu próprio movimento ascendente e pela sua vizinhança invasiva, ameaça entrar por todas as brechas da vida cultural, pondo em cheque a própria concepção de arte do intelectual erudito. ${ }^{12}$

O problema era, portanto, o da concepção do que era e do que não era arte, do que podia e do que não podia ser ouvido; um problema nada novo, proposto pela primeira vez por Platão na República. O que o Ensaio fornece de mais instigante é a defesa de uma identidade que já existia. Havia um tipo de Brasil oculto pela excessiva valorização do que vinha do exterior. Era o caso de apenas desvelar essa essência, tarefa que Mário propunha aos compositores nacionais. Já vimos como ele imaginou a incorporação do material folclórico, e de como ele reagia diante da chegada dos meios de comunicação de massa.

Essas questões foram largamente tratadas pela recepção da obra de Mário de Andrade, mas aparentemente sem nunca descuidar da proposta nacionalista. Ou de tomá-la sempre em primeiro plano. O que sugerimos aqui, na esteira da aproximação com Adorno, é que o que há de mais perene nas afirmações de Mário pode ser justamente aquilo que era visto por Adorno como fruto da domesticação: a arte comercial derivada da música folclórica, popular.

Oneyda Alvarenga nos dá a idéia exata da importância da técnica e da educação musical que Mário tanto exaltava.

Assim agiu como poeta, não só levando para os seus versos aquelas mesmas pesquisas da língua e a ambiência nacional, mas fazendo penetrar neles, em larga dose, elementos líricos, versos-feitos, versos e técnicas hauridos na poética popular brasileira. Assim agiu auxiliando todas as artes no Brasil, com estudos carinhosos das suas obras e dos seus criadores. E assim o encontramos na música também. Seus escritos sobre ela constituem uma obra nacionalizadora ou uma luta pela melhoria do nosso nível de cultura musical. Foram feitos, de um lado, para dar sistematização intelectual às experiências dos compositores ocupados na criação da música erudita brasileira ou para apontar caminhos que auxiliassem esses compositores no seu esforço útil. De outro lado, visavam uma orientação melhor do ensino da Música, a moralização profissional do músico, a difusão musical intensa. ${ }^{13}$

Seu comentário aponta bem de perto para aquilo que Adorno muito valorizou, e pelo qual foi considerado um esteta burguês, a valoração da estrutura. Ambos, Mário e Adorno, eram músicos formais, dominavam a técnica e achavam que ela era determinante para a feitura da música. O que hoje causa certa estranheza é que o olhar de Adorno sobre o jazz pode ser perfeitamente compreendido, na medida em que ele via naquela representação formatada para o cinema e o rádio um adormecimento de instintos profundos e primitivos. Mas nem sempre entendemos a resistência de Mário contra a música comercial, distinta da experiência estadunidense e, como viria a se comprovar, muitas vezes um antídoto inoculado dentro da indústria cultural e por vezes financiado por ela. 
O musicólogo paulista deveria ter ido mais longe nesse ponto, já que conhecia as diferenças entre a esfera erudita e folclórica, apontou essas diferenças, só que, diferente de Adorno, queria fundi-las. Talvez não o tenha feito ele mesmo porque seu talento musical como pianista foi abortado por um problema familiar, a morte precoce de um irmão. Como mostra Oneyda Alvarenga, Mário ainda assim levou a cabo seu projeto estético e compôs peças literárias a partir de referências culturais folclóricas, populares, como ele as definia. Macunaíma é a maior prova desta realização. ${ }^{14}$ Depois deu todas as indicações de como isto deveria ser feito no terreno musical. Uma história de vida e de promessas muito próxima de um jovem e idealista alemão que via na arte a única possibilidade de redenção da derrocada moderna, Nietzsche. O grandioso, o mito, o essencial da cultura brasileira estava oculto, mascarado por nossa falta de tradição artística, aos compositores nacionais restava revolver essas profundezas e delas criar a arte máxima, que deveria expressar a nação e o povo de modo a afirmar aquilo que possuíam de mais belo e trágico. Um programa romântico jamais realizado.

\footnotetext{
* Henry Burnett é compositor e professor adjunto do Departamento de Filosofia da UNIFESP.

** Uma primeira versão deste texto foi publicada na revista eletrônica Trópico: idéias de norte a sul. Agradeço aqui ao editor Alcino Leite Neto, pelo acolhimento. Esta versão em formato de ensaio foi revista e ampliada.
}

${ }^{1}$ ADORNO, T. Philosophie der neuen Musik. Frankfurt am Main: Suhrkamp, 2003, p. 9.

2 Sobre o envolvimento de Adorno nesse projeto de pesquisa sobre o rádio nos EUA, sugiro a leitura do artigo de Iray Carone, "Adorno e a música no ar: The Princeton Radio Research Project". In: Tecnologia, cultura e formação... ainda Auschwitz. São Paulo: Cortez, 2003.

${ }^{3}$ DUARTE, R. Teoria crítica da indústria cultural. Belo Horizonte: UFMG, 2003, p. 192. Sobre o tema do folclorismo em Adorno, sugiro o capítulo "Estabilização". In: ALMEIDA, J. Crítica dialética em Theodor Adorno: música e verdade nos anos vinte. São Paulo: Ateliê Editorial, 2007.

${ }^{4}$ ANDRADE, M. "Música popular" ("Estado”, 15.01.1939). In: Musica, doce música. São Paulo: Martins, pp. 280-281.

${ }^{5}$ Idem, Ensaio sobre a música brasileira. São Paulo: Martins, 1962, p. 26.

${ }^{6}$ ADORNO, T. "O fetichismo na música e a regressão da audição". In: Benjamin, Habermas, Horkheimer, Adorno. São Paulo: Victor Civita, p. 172.

${ }^{7}$ ANDRADE, M. "Música popular” (“Estado”, 15.01.1939). Op. cit., p. 280.

${ }^{8}$ MALHEIROS DOS SANTOS, P. S. Músico, doce músico. Belo Horizonte: UFMG, p. 16.

9 Ibidem, pp. 17-18.

${ }^{10}$ ANDRADE, M. Aspectos da música brasileira, p. 138.

${ }^{11}$ Idem, Ensaio sobre a música brasileira. Op. cit., pp. $16 \mathrm{ff}$.

12 WISNIK, J. M. "Getúlio da Paixão Cearense (Villa-Lobos e o Estado Novo)". In: O nacional e o popular na cultura brasileira. São Paulo: Brasiliense, 1983, p. 133.

${ }^{13}$ ALVARENGA, O. Mário de Andrade: um pouco. Rio de Janeiro: José Olympio, 1974. 
${ }^{14}$ Ver MELLO E SOUZA, G. O tupi e o alaúde. São Paulo: Editora 34, 2003. 